\title{
Participación social: el qué y los cómos en la cuestión espacial
}

\author{
Todo lo que tengo \\ y lo que no tengo \\ lo tengo \\ y no lo tengo \\ de pie
}

Víctor Casaus

E: probable que todas las poblaciones hacia mediados de este siglo terminen por invocar l derecho a la ciudad, convirtiéndolo definitivamente en un símbolo de lucha para la transformación de la vida, o tal vez, en la ideología reformadora para la formalización final de lo no controlado por la urbanización del capital (que asoma con rostro humano). Pero hablemos sobre lo que nos llama hoy en el mundo, para caminar hacia un territorio socialmente justo y equilibrado. Es decir, el lugar donde las relaciones de la humanidad con la naturaleza y sus recursos finitos permitan un desarrollo sostenible en el tiempo, de modo que se incluya a los procesos de urbanización en la supervivencia del ecosistema; y no al revés, que la urbanización planetaria incorpore artificialmente procesos ecológicos y de eficiencia en una sociedad cada vez más depredadora.

Pues bien, pensando en ese llamado primero de derecho a la ciudad, para no quedar tan mal con nuestra generación, y sobre todo, para cumplir con las próximas, la democracia actual, aunque imperfecta, ha creado mecanismos de participación que evolucionan según el grado de desarrollo de una comunidad. Así, podemos pensar que la participación social es la esencia de la actitud política del ser humano, pero en la medida en que más y más población demanda su participación en las decisiones sobre su entorno, nos atrevemos a creer que la participación masiva de la sociedad es la política misma.

Entonces, estaremos de acuerdo, hasta con el más codicioso deseo humano, que una sociedad menos desigual y más sustentable debería ser un proyecto común traducido en la cuestión espacial, siendo este quizás, el [qué] más importante a considerar por los pueblos que evolucionan debido a su acción práctica (cotidiana, artística), técnica y disciplinar. En esta dirección, las comunidades humanas han activado a través de la historia procesos de innovación y organización social que han rebasado desde siempre los simulacros de participación institucionalizada; pero inmersas en un sistema de desarrollo desigual, que lamentablemente no ha permitido la transformación de sus condiciones objetivas de penuria y miseria.

En tal sentido, las comunidades no pueden ni deben retroceder frente a autoritarismos de cualquier signo, por más que se recubran de democracia o legalidad, presentes en el seno de concejos o en cámaras de pseudo representantes que tienden a definir la participación por su ejercicio mínimo y son capaces de reducirla a la aldea de la socialización al sacrificio de la escucha, o a la ilusión de mesas programadas de especialistas convocadas para confirmar respuestas, mas nunca sospechar de las preguntas.

En nuestros días, la cuestión espacial exige la responsabilidad de participación del morador que ejerce la práctica del habitar, ya no como quien delega su destino a los órganos "representativos", sino como quien vive la realidad del campo y la ciudad bajo sus pies y sobre sus hombros; y por tanto, conoce, desea, sufre, goza y decide la producción de su espacio cotidiano y simbólico. En esta perspectiva, parece ser que entendemos lo que va a permitir que caminemos juntos con nuestras diferencias. Sin embargo, al tener que hacernos cargo de lo urbano y lo territorial, es alrededor de los cómos por donde debemos seguir trabajando para ensanchar el camino sin perder ese [qué] inicial.

Los temas que se tratan en esta edición observan la realidad con diferentes lentes de análisis y aplicación, recorriendo los campos de la teoría e historia de la arquitectura y de la ciudad, los estudios urbanos con énfasis en la recuperación ambiental y paisajística, la ordenación del territorio, la conservación del patrimonio industrial y arquitectónico, la vivienda social y la academia en movimiento. Así, Estoa cumple su vigésima edición, confiando en la importancia de promover y multiplicar los cómos para llevar adelante la estrategia del conocimiento que, a su vez, posibilite a la sociedad avanzar hacia un destino común en el espacio del futuro.

A través de esta editorial, se expresa también la magnífica salud de la revista, luego de nueve años de ediciones semestrales ininterrumpidas y una angustiosa pandemia que no acaba. En demostración de ello, Estoa ha emprendido el desafío de someter la revista a nuevas indexaciones, llegando con su cuarto número consecutivo sin rastros de endogamia académica, reforzando sus Consejos con nuevos miembros de la comunidad científica internacional, apostando por una nueva tendencia de visibilización, mediante el primer concurso de fotografía sobre sus líneas de investigación, promovido en las escuelas de arquitectura a nivel nacional para hallar su portada y contraportada. Y fundamentalmente, por la publicación de estos catorce artículos producidos desde la diversidad científica iberoamericana.

Pedro Jiménez-Pacheco pedro.jimenezp@ucuenca.edu.ec

Cuenca, julio de 2021 